\title{
Osteoporosis: Diagnosis and Management
}

\section{Rangga Rawung, ${ }^{1}$ Raynald G. Bagy ${ }^{2}$}

\author{
${ }^{1}$ Division of Orthopaedics, Department of Surgery Faculty of Medicine Sam Ratulangi \\ University - Prof. Dr. R. D. Kandou Hospital, Manado, Indonesia \\ ${ }^{2}$ Medical Doctor Program, Faculty of Medicine, Sam Ratulangi University, Manado, \\ Indonesia \\ Email: raynaldbagy011@student.unsrat.ac.id
}

\begin{abstract}
Abstrak: Osteoporosis merupakan penyakit tulang yang paling sering dijumpai dan memiliki hubungan erat dengan risiko fraktur sehingga merupakan salah satu masalah kesehatan masyarakat yang besar. Penyakit ini lebih sering ditemukan pada perempuan usia lanjut dan dipengaruhi oleh berbagai faktor. Tulisan ini merupakan suatu kajian pustaka dengan tujuan untuk menyampaikan konsep dasar dan pemahaman yang lebih baik yang dibutuhkan dalam pengelolaan penyakit ini. Hasil kajian menunjukkan bahwa pengelolaan penyakit ini membutuhkan strategi tatalaksana yang harus disesuaikan pada setiap pasien, yang meliputi modifikasi gaya hidup, pengelolaan faktor risiko dan terapi farmakologis agar dapat menurunkan morbiditas dan mortalitas serta komplikasi yang ditimbulkan oleh penyakit ini. Dibutuhkan penelitian lanjut untuk memberikan bukti dan memberikan pedoman agar pengelolaan penyakit dapat menjadi lebih baik.
\end{abstract}

Kata kunci: osteoporosis, risiko fraktur, densitas mineral tulang

\begin{abstract}
Osteoporosis is the most commonly bone disease and is highly associated with an increased risk of future fracture furthermore makes it a major public health problem. The disease is most prevalent in older females with multifactorial etiology. This was a literature review using relevant articles. The aim of this study was to provide basic concept and better understanding which is needed to manage the disease. This review showed that individualized treatment strategy is needed. Lifestyle modification, risk factor management, and pharmacological treatment are required to deal with the condition as well as reduced morbidity and mortality caused by the disease and its complication. Further study of this disease needs to be conducted to provide more evidences and guidelines to achieve better management of the disease.
\end{abstract}

Keywords: osteoporosis, fracture risk, bone mineral density

\section{Introduction}

Osteoporosis is a clinical systemic skeletal disorder of decreased bone strength characterized by abnormality of bone mass and microarchitecture of bone structure, resulting increased bone fragility and subsequently increased fracture risk. Decreased bone strength is multifactorial in addition bone mineral density (BMD) including rates of bone turnover, bone geometry, and microarchitecture..$^{1,2}$

Osteoporosis is the most commonly bone disease found in humans, furthermore makes it a major public health problem. Everyone can be affected by the disease regardless one's sex, race, and age, but its prevalence will increase as the individual ages. $^{3}$

Many authors have suggested that osteoporosis is highly associated with an increased risk for a future fracture. Moreover, it is a silent disease until fractures occur, which causes important health problems, morbidity, and even death. Therefore, it is important for clinician to recognize and be proactive in the 
management to prevent future fracture in patient with osteoporosis in order to decreased morbidity and mortality and improve patient's quality of life. The purpose of this paper is to describe osteoporosis thoroughly and provide a basic framework for workup and management of the disease. ${ }^{4}$

\section{Classification}

Osteoporosis is defined operationally according to bone mass, measured as bone mass density (BMD). World Health Organization (WHO) classify osteopenia and osteoporosis on the basis relationship of fracture risk to BMD. The criteria are divided to normal, osteopenia, and osteoporosis. Normal criterion is characterized by BMD 1 standard deviation or less below that of reference mean ( $t$ score of -1 or greater). Osteopenia is characterized by BMD between 1 and 2.5 standard deviations below that of reference mean ( $\mathrm{t}$ score between -1 and-2.5). Moreover, osteoporosis is characterized by BMD more than 2.5 standard deviations below that of reference mean $(t$ score less than -2.5$){ }^{5}$

Furthermore, WHO defined thresholds of bone mineral density, on the basis of the association of fracture risk to bone mineral density:(6) In osteoporosis, the BMD is 2.5 standard deviations or more below the mean ( $t$ score of -2.5 or less). In severe or established osteoporosis as stated that osteoporosis by definition mentioned earlier ( $t$ score of -2.5 or less) and addition of 1 or more history of fragility fractures. Osteoporosis clinically is also defined based on low BMD (osteopenia) that is between 1 . and 2.5 standard deviations below the mean ( $\mathrm{t}$ score between -1.1 and -2.4 ) in individual with history of fragility fracture. Noted that comparator population for $t$ score has varied across literatures regarding gender and racial matching. ${ }^{6}$

\section{Etiology and risk factors}

Osteoporosis is a multifactorial disease. It is most prevalent in older females mainly in postmenopausal period, but some males are also at high risk. Risk factors of both sexes include age more than 65 years, smoking, family history of fracture, and abnormal body mass index. Secondary causes of osteoporosis include chronic treatment with glucocorticoids, gastrointestinal disorders, diabetes mellitus, rheumatoid arthritis, liver disease, gluten enteropathy, and multiple myeloma and other hematologic disorders. ${ }^{7}$

Risk factors of osteoporosis are divided into two categories based on modifiable feature, as follows: modifiable risk factors and non-modifiable risk factors. ${ }^{8}$

\section{Modifiable risk factors}

Modifiable risk factors consist of lack of physical activity, intake, less sun exposure, consumption of drinks high in caffeine and high in alcohol, use of glucocorticoid, and tobacco smoking. ${ }^{9-17}$

Lack of movement or exercise will hinder the process of bone mass formation, therefore, BMD will reduce. ${ }^{9}$

Good daily intake could decrease the impact of osteoporosis and other chronic diseases. There is evidence that high quality of nutritional status with appropriate daily intake of fruit, vegetable, and any food containing protein, calcium, and vitamin D has a positive effect on bone quality. Conversely, high-caloric and high alcohol intake has been associated with lower bone mass and higher rate of fracture. Dietary pattern with high daily intake of dairy products, fruits, and whole grains has been proven to contribute positively to bone health. Moreover, good dietary planning could have potential effect in encouraging bone health. While lack of vitamin K, especially vitamin $\mathrm{K} 2$, leads to deterioration of calcium removal and aggravates risk of calcification of blood vessels. Increased vitamin $\mathrm{K} 2$ intake has been proven to mitigate calcium-associated health risks. ${ }^{10}$

Less sun exposure in related to vitamin D deficiency is associated with diseases such as osteoporosis and may contribute to bone fractures. Vitamin D can be obtained not only from dietary source, but also synthesized in the skin by sunlight exposure. It is important to ensure adequate exposure 
to the sun since it is the main source of vitamin $\mathrm{D}$ besides the dietary source. ${ }^{11}$ Consumption of drinks high caffeine and high alcohol can cause bone loss, as well as brittle and damaged bone. High consumption of caffeine and alcohol can inhibit the process of bone mass formation and are toxic to the body. ${ }^{12,13}$

Glucocorticoids tend to decelerate bone formation and accelerate bone resorption. They decrease differentiation and maturation of osteoblasts which are important for bone formation, further decrease their number and roles. Moreover, large amount of glucocorticoid leads to osteoblast apoptosis, and is responsible to reduced bone formation. Osteocytes involved in microdamage repair of the bone are also going to undergo apoptosis and, furthermore, decrease bone strength and quality. Gluco-corticoids also expand the expression of cytokines, especially receptor of activator of NF-kappa $b$ ligand (RANKL), that play a role in differentiation of osteoclasts and later decrease the inhibition of osteoclasts, leading to increased bone resorption. Glucocorticoids also contribute to bone loss by indirectly decrease calcium resorption, suppress growth and sex hormones, and alter parathyroid hormone. Still, subclinic secondary hyperparathyroidism increases bone resorption. There is a hypothesis suggesting genetic factors that may take part to make an individual more susceptible to adverse effects of glucocorticoids, but it still far reaching to conclusion. ${ }^{14,15}$

Tobacco smokers are very susceptible to osteoporosis because tobacco contains active substance which interferes with bone absorption and as well as the levels and activities of the hormones, hence the composition of bone cells becomes weak. Tobacco smoke alters bone mass by altering body mass, parathyroid hormone-vitamin D metabolism system, adrenal hormones, sex hormones, and increase stress oxidative on the bone. In addition, tobacco influences bone mass directly on osteogenesis and angiogenesis processes of bone. ${ }^{16,17}$

\section{Non-modifiable risk factors}

Non-modifiable risk factors consisted of family history, gender, age, race, and estrogen deficiency. ${ }^{18-26}$

Bone mass density of postmenopausal women is highly associated with many inherited genetic matter risk factors. In various investigation, many authors suggested hereditary matters as one of the most significant hazard factors of osteoporosis. It is accepted that hereditary variables influence the long term bone thickness most extreme as long as 25 years old. ${ }^{18}$

Family history of osteoporosis and fracture is highly associated with for osteoporosis risk. The record of prior fracture and family history of osteoporosis in close family members (frequently mother) are important indicators of hazard to future osteoporosis in postmenopausal women. ${ }^{18}$

Osteoporosis is more commonly found in women, especially in old age due to a decrease in estrogen. Pregnant women have also a high risk of osteoporosis because the fetal development process requires a lot of calcium. ${ }^{19,20}$

Osteoporosis is usually considered as a disease of the elderly with low BMD and its prevalence increasing with age. Aging process alters bone structure, function, and composition and further causes osteoporosis. Identification of aging process on osteoporosis can be detected as early as an individual aged 40 years. ${ }^{21,22}$

White race and Asian descent have a higher predisposition to osteoporosis. This is generally caused by low calcium consumption. In addition, lactose intolerance which causes a lack of consumption of animal products increases the risk of this disease. $^{23,24}$

Estrogen deficiency is associated with osteoporosis. Estrogen deficiency is the primary cause of bone loss in women after menopause and during several year preceding the actual menopause, similar to that observed in the early postmenopausal years. Women with lower concentrations of residual estrogen have more progressive bone loss and fracture, although this might 
be confounded by the effect of body weight or other sex steroids. In addition, women with breast cancer receiving aromatase inhibitors as adjuvant therapy tend to lose bone and sustain an increased rate of fragility fracture. ${ }^{25}$

The mechanism of estrogen role in osteoporosis is suggested by estrogen receptor- $\alpha(\mathrm{ER} \alpha)$. Osteoblasts and osteoclasts mediate the estrogen's defence effect in cortical and cancellous bone. Osteoblasts $\mathrm{ER} \alpha$ stimulates cortical bone accrual in response to mechanical strain, independently of estrogens. Estrogens prolong osteoblast and osteocyte survival by attenuating apoptosis which is important in shortening the lifespan of osteoclasts. They also influence lifespan of osteocytes as longlived cells located in the matrix and play some roles in the homeostatic adaptation of bone to mechanical forces. ${ }^{26}$

\section{Epidemiology}

Osteoporosis can be found worldwide and still be a major public health problem, especially in developing countries. There were 200 million people suffering from osteoporosis worldwide. Moreover, 20-25 million of population, 1 of 2-3 post-menopausal women and more than $50 \%$ of the population over the age of 75-80 years affected by osteoporosis. Compared with people in African countries, European and Asian societies had lower bone density, which means increased susceptibility to osteoporosis. The white paper study conducted with the Indonesian Osteoporosis Association in 2007 suggested that the proportion of individuals affected by osteoporosis aged over 50 years was $32.3 \%$ in women and $28.8 \%$ in men. The incidence of upper femoral fractures due to osteoporosis at the age of 40 in Indonesia is around 200 out of 100,000 cases. $^{27}$

In the perspective of National Osteoporosis Foundation (NOF), United States has more than 10 million adults age 50 years and older had osteoporosis and more than 43 million had low bone mineral density in 2010. Within 1 year after being diagnosed with a new osteoporotic fracture, about $15 \%$ of them were affected by one or more subsequent fractures and $20 \%$ more or less of them died. Mortality in those with hip fracture have the largest number, $30 \%$ of them will die within 12 months. ${ }^{28}$

\section{Clinical Manifestation}

Apparently, osteoporosis does not show any clinical manifestations until it progresses to a fracture. This stereotype leads many patients with osteoporosis misinterpret their disease because of not having any signs and symptoms. On the other hand, many patients with mild hip or foot pain believe that they are having osteoporosis. This statement could not be translated to no-fracture status. As a comparison, pain in the absence of fractures or other bone deformities is more related to another bone disease such as osteomalacia. ${ }^{29}$

Vertebral fracture is commonly found as an apparent clinical manifestation of osteoporosis. Approximately two of three vertebral fractures reported no symptom. and they are diagnosed in imaging of chest or abdominal incidentally. Hip fractures are also commonly found, approximately found 15 of 100 women and 5 of 100 men in their eighties. Upper extremity fractures such as Colles fractures may also occur. These kind of fractures are more likely found in postmenopausal women. ${ }^{30,31}$

Patients with osteoporosis fractures usually report a history of no or only minimal trauma that produce pain. Patients may only complain of fall from a standing or sitting position. Some characteristics of pain related to osteoporosis are, as follows: localized to a specific vertebral level from mid-to-lower thoracic spine until upper lumbar; characterized as stabbing or dull pain, exacerbated by motion; in some cases, pain radiates to the abdomen; in many cases, it leads muscle spasms and is aggravated by activity and vice versa; and had very limited daily activity due to pain exacerbated by motion. ${ }^{29}$

Patients with chronic hip fracture may complain pain in the medial knee, medial thigh, anterior thigh, posterior buttock, and/or groin during weight-bearing activity; 
very lacked of range of motion, particularly internal rotation and flexion; and involved hip usually external rotated in the resting position. ${ }^{32}$

\section{Diagnosis and Fracture Risk Assessment}

In the USA, T-score of $\leq-2.5$ at the lumbar spine, femur neck, or total hip by BMD examination is the standard criteria to establish diagnosis of osteoporosis. As Tscores declined, the relative risk for fracture is inversely affected. This T-score can project risk of future fracture and gives and established a diagnosis of osteoporosis. In addition, a fracture risk algorithm known as FRAX is an alternate to point out individuals with high fracture risk, as well as the several types of low-trauma fracture phenomenon. It had been proposed that some of these ways of predicting an increased fracture risk should also enable the use of the diagnostic term osteoporosis. ${ }^{33}$

World Health Organization recommends FRAX as a mean to diagnosis osteoporosis. This FRAX involves femoral neck (hip) BMD, age, gender, body weight and height, fracture history, past illness related to bone loss, steroid use, smoking status, and alcohol intake based on individual nationality. FRAX is a useful tool to calculate 10-year risk of a hip fracture or other osteoporotic fracture (spine, extremities) in men and women 49-90 years of ages that never take account to any bone management before. National Bone Health Alliance Working Group suggested that postmenopausal women and also men over 50 years of age should be diagnosed as having osteoporosis if they showed a greater risk for fractures. They also recommended the BMD testing and the finding of a T-score of $\leq-2.5$ at the spine or hip as one way to make the diagnosis. ${ }^{33}$

\section{Examination}

If a patient has vertebral body fracture, he/she should be suspected as at risk for osteoporosis with back pain or kyphosis. Due to their no clue of complaints as osteoporosis presentation, imaging vertebral screening for the following characteristic of patients is recommended by National Osteoporosis Foundation: women $>70$ years old and men $>80$ years old, osteopenia based on BMD measurement in women aged 6569 and men aged 75-79, and low energy traumatic vertebral body fracture or decreased actual height in postmenopausal women aged 50-64 and men aged 50-69. ${ }^{2}$

\section{Dual energy X-ray absorptiometry (DEXA)}

Dual energy $X$-ray absorptiometry (DEXA) is the main technique used to measure BMD. It has a high sensitivity of calcium by absorbing X-rays to evaluate the relative quantity of bone and other soft tissue, furthermore, to calculate mineral content and density of the bone. One must undergo several measurements on the same machine to recognize true changes of his/her BMD because every machine has its own standardization. This DEXA can be used to evaluate bone mineral density at various body sites. Usually, clinicians identify four potential sites at the hip (total hip, femoral neck, trochanteric region, and Ward's triangle) to measure fracture risk because density of the hip has a high precision, reproducibility, and is mostly correlated to the risk. Some body regions such as lumbar spine is also highly accurate, unfortunately, it is heavily disturbed by artefacts. The upper extremities include radius and ulna may be used as an alternative when the primary site cannot be measured or interpreted. Unfortunately, there are significant dissimilarities between the dominant and non-dominant extremities in BMD measurement. Current evidence shows that hip's BMD is the most accurate for predicting a fracture risk. Moreover, followup treatment is highly recommended to use spinal BMD. ${ }^{34}$

\section{CT-Scan}

Quantitative CT-scan could reconstruct a three-dimensional image and calculate the BMD with an object of known density as a comparison. CT scan evaluates the true volumetric BMD and is not affected by the individual size or deformities. Quantitative CT may also be used to assess patients with 
presume of having false elevated BMD on DEXA such as osteoarthritis cases. Unfortunately, CT-scan has higher radiation, inconsistent, and fewer standardized reference ranges and analysis protocols. Moreover, peripheral quantitative CT requires machines specifically designed for distal bone sites (usually radius or tibia). There are more techniques and method of CT used in special population and condition, although it is currently limited to some research centers. ${ }^{34}$

\section{Management}

The principal aim of osteoporosis treatment is to prevent fragility fractures and increase patient's quality of life. Thus, the ability to assess fracture risk is critical in identifying patients who are eligible for intervention. ${ }^{1}$ The management of osteoporosis consists of non-pharmacological and pharmacological treatments. ${ }^{35,36}$

\section{Non-pharmacological Treatment}

The first line management of osteoporosis is lifestyle modification which is useful to prevent complication of disease. Increase level of physical activity; advise regular weight-bearing, muscle strengthen, and balance training, tailored to the individual patient; ensure adequate dietary calcium intake and vitamin D status; advise appropriate daily calcium intake best achieved through diet; identify and modify risk factors for falls such as visual acuity, avoid medication affecting balance, decrease fall threat in environment (slippery footwear, inadequate lighting, hurdle); avoid smoking; and decrease alcohol intake. $^{35}$

\section{Pharmacological Treatment}

Antiresorptives is the most commonly medications used to treat osteoporosis, it works by reducing resorption further slow bone turnover. These antiresorptive groups include bisphosphonates, selective estrogen receptor modulators (SERMs), denosumab, estrogen, and calcitonin. The only anabolic agent that stimulates bone formation is teriparatide. ${ }^{36-46}$
There are some prescription assessment primers to help in examination of each adequacy. Subsequently, choice of medicine should be established by considering reduced BMD or conceivably split, riskbenefit ratio, and contraindications. Without any contraindications, oral bisphosphonate is suggested as the first-line treatment due to the accessibility and evidence of its long term wellbeing. ${ }^{36}$

\section{Bisphosphonates}

Oral bisphosphonates (alendronate, risedronate) are ordinarily the first choice for most patients because of ease and considerable proof in reducing fracture risk. Bisphosphonates work by easing back bone turnover and further reducing risk fracture in all locales. The oral bisphosphonates alendronate and risedronate could reduce the hazards of vertebral and hip fractures by around half, and nonvertebral fracture by $30 \%$. Intravenous (IV) zoledronate diminishes the hazard of vertebral fracture by $70 \%$, hip fracture by $40 \%$, and nonvertebral fracture by $30 \%$. Oral and IV ibandronate declines vertebral fracture hazard by half; however, currently, there is lack of information about its efficacy to reduce hip and nonvertebral fractures. ${ }^{36,37}$

\section{Selective Estrogen Receptor Modulators (SERMs)}

SERMs tied to estrogen receptors play a role as agonist and antagonist of estrogen relying upon the target organ. Raloxifene has been proved of wellbeing properties over years and lessen the likelihood of vertebral fracture. Nowadays, there is lack of information about its efficacy to reduce fracture in improvement of hip and nonvertebral fractures. ${ }^{38}$

SERMs bind to estrogen receptors and have estrogen agonist and antagonist effects depending on the target organs. Raloxifene has more than 8 years of safety and fracture data and decreases the risk of vertebral fracture. There are inadequate data to support fracture reduction at hip and nonvertebral sites. Ideal recipients for raloxifene include women who incorporate, 
cannot tolerate bisphosphonates, but are not at high risk for venous thromboembolism (VTE) or stroke. Other options of selective estrogen receptor modulator is bazedoxifene. ${ }^{1,38}$

\section{Teriparatide}

Teriparatide or recombinant human 134 parathyroid hormone is the only osteoporosis drug that roles as an anabolic agent. Primarily, it works by activating bone remodeling in addition to reduce bone turnover. Evidence showed that there was a decrease of vertebral fractures risk by $70 \%$ and nonvertebral fractures risk by $50 \%$; however, there are lack of data to show hip fracture reduction. The BMD gain occurs in the initial periods of treatment; in any case, it takes approximately a half year before its anti-fracture properties adequately occurs. Teriparatide ought to be halted following 2 years of treatment in light of the fact that the advantages on BMD start to level off following year and a half of treatment. Moreover, animal models and one human case report indicated a higher risk of osteosarcoma in longer-term treatment, in spite of the fact that causality among teriparatide and osteosarcoma was not set up in another case report. Consequently, teriparatide should to be kept away from patients with greater risk of osteosarcoma (history of Paget infection, bony radiation, skeletal metastases, etc). ${ }^{1,39}$

The most indication for teriparatide includes postmenopausal women with severe vertebral osteoporosis $(\mathrm{T}<3.5$, or $\mathrm{T}$ $<2.5$ plus fragility fracture). Since earlier bisphosphonate use may dull the impact of teriparatide, it would be better to be utilized first with an arrangement to progress using an antiresorptive agent, for example, a bisphosphonate or SERM following 2 years of treatment. However, teriparatide is incredibly costly. ${ }^{39}$

Common side effects found on this medication were cephalgia, myalgia, nausea, hypercalcemia, and hypercalciuria, therefore, it ought to be avoided in patients with a past illness of nephrolithiasis or hypercalciuria. Uric corrosive levels can likewise an increment and may hasten a gout assault, in this way, not to use teriparatide until uric corrosive levels are controlled to under 7.5 $\mathrm{mg} / \mathrm{dL}$ in patients with a background marked by gout. Before starting treatment serum calcium, phosphate, creatinine, alkaline phosphatase, albumin, 25-OH, and uric acid have to be checked. If there is a chance that hypercalcemia or hypercalciuria presents, primary hyperparathyroidism has to be assessed. Vitamin D deficient has to repleted before starting treatment. ${ }^{40}$

\section{Denosumab}

Denosumab is a monoclonal antibody that hinders osteoclast arrangement and prevents resorption. Like bisphosphonates, it can lower all kinds of fracture. Primary indication of this drug includes osteoporotic postmenopausal women who are intolerant or non-adherent to different drugs, or those with kidney disease (regardless of whether creatinine clearance is $<35 \mathrm{~mL} / \mathrm{min}$ ). ${ }^{41,42}$

Side reactions such as musculoskeletal pain, hypercholesterolemia, and cystitis are commonly found in this medication. Hypocalcemia has to be excluded before administering denosumab and vitamin D level has to be corrected before therapy. Information about long-term safety and risk of this medication is still limited. Additionally, there is lack of information on the thought term of denosumab treatment or on successive treatment with different osteoporosis drugs. ${ }^{43}$

\section{Hormon Replacement Therapy}

Currently, hormone replacement therapy (HRT) is not a routine use as a prevention or treatment of osteoporosis due to the increased risks of diseases such as breast cancer, stroke, venous thromboembolism, and coronary heart disease, Women's Health Initiative suggested an increased risk of congestive heart disease, cerebrovascular disease, venous thromboembolism, and breast cancer in women using a combination of estrogen and progestin therapy. Nonetheless, some women who are intolerant to other anti-osteoporotic drug or who have perimenopause symptoms, they may be 
considered to administer HRT. Evidence suggested that risk fracture reduction of $30 \%$ to $40 \%$ in hip, vertebral, and nonvertebral fractures due to HRT administration. Despite the fact that HRT is not affirmed by FDA for the treatment of osteoporosis, some study suggested that there is some fracture reduction in osteoporotic women. ${ }^{1,44}$

\section{Calcium and Vitamin D Supplementation}

The use of calcium and vitamin D supplementation for osteoporosis prevention is still controversial due to the potential increased side effect in cardiovascular and kidney. As secondary prevention, there were some evidence showed that combination of calcium and vitamin $\mathrm{D}$, not only vitamin $\mathrm{D}$, decreased fractures risk in osteoporotic individual. Daily calcium intake recommended for patients with osteoporosis is $1200 \mathrm{mg}$, ideally through diet in addition to 800 IU of vitamin D. Since calcium supplements can alter bisphosphonate absorption, ensure patient to take this supplement and oral bisphosphonates separately. Mainly, calcium carbonate is recommended in account of low cost. Patients who take medication that block gastric acid, or plan to take the supplements separately with meal, should take calcium citrate due to an acidic environment is needed for absorption. It is noted that normal vitamin D level is a must before starting treatment because efficacy of bisphosphonate therapy is the best in individual with serum 25-hydroxyvitamin D (25-OH) levels of $>33 \mathrm{ng} / \mathrm{mL} .^{45,46}$

\section{Follow-up}

To date, there is no concession to proposed follow-up treatment of osteoporosis. There were controversies about how BMD changes while on treatment associated with decreased risk of fracture. A few investigations suggested that the more prominent the improvement in $\mathrm{BMD}$, the more decreased fracture risk. On the other hand, different studies suggested that lower fracture incidence is independently of BMD in the treatment. Most subspecialist associations such as the NOF and the North American Menopause Society, suggest to perform DXA examination every year in first two years since treatment started. The next follow up is individualized due to the improvement in BMD or whether the patient is at risk for progressively fast decrease of BMD due to side reaction or past illness. In case that a follow-up DXA is applied, clinician's decision upon the outcomes relies on patient's characteristic. If the BMD is progressively declining, monitor prescription adherence and ensure that the patient has got appropriate calcium and Vitamin D supplementation. Preventing complication is the main goal of management patient with osteoporosis. $^{47}$

\section{Conclusion}

Osteoporosis remains a challenge due to its worldwide distribution and asymptomatic characteristic. Once it gets symptommatic, the disease becomes complicated leading to higher morbidity rate, change of one's lifestyle, and impairment of quality of life. Since the disease is multifactorial, multidiscipline and individualized approach are needed to treat patient and prevent any damaging impacts.

\section{Conflict of Interest}

The author affirms no conflict of interest in this study.

\section{REFERENCES}

1. Sözen T, Özışık L, Başaran NÇ. An overview and management of osteoporosis. Eur $\mathbf{J}$ Rheumatol. 2017;4(1):46-56.

2. Farmer RP, Herbert B, Cuellar DO, Hao J, Stahel PF, Yasui R, et al. Osteoporosis and the orthopaedic surgeon: basic concepts for successful co-management of patients' bone health. Int Orthop. 2014;38(8):1731-8.

3. Camacho PM, Petak SM, Binkley N, Diab DL, Eldeiry LS, Farooki A, et al. Guidelines for the diagnosis and treatment of postmenopausal osteoporosis - 2020 update. Endocrin Pract. 2020;26(Suppl 1):1-46.

4. Qaseem A, Forciea MA, Mclean RM, Denberg TD. Treatment of low bone density or osteoporosis to prevent fractures in men and women : a clinical practice guideline update from the American College 
of Physicians. Ann Intern Med. 2017; 166(11):818-39.

5. Kanis JA, on behalf of the World Health Organization Scientific Group. Assessment of osteoporosis at primary health care level. Technical Report. WHO Collaborating Centre, University of Sheffield, UK. Available at www.shef. ac.uk/FRAX/index.htm

6. Compston J, Cooper A, Cooper C, Gittoes N, Gregson C, Harvey N, et al. UK clinical guideline for the prevention and treatment of osteoporosis. Arch Osteoporos. 2017;12(1):43.

7. Pouresmaeili F, Kamalidhghan B, Kamarehei M, Goh YM. A comprehensive over-view on osteoporosis and its risk factors. Ther Clin Risk Manag. 2018;14:2029-49.

8. Alejandro P, Constantinescu F. A review of osteoporosis in the older adult: an update. Rheum Dis Clin North Am. 2018;44(3):437-51.

9. Rodríguez-Gómez I, Mañas A, Losa-Reyna J, Rodríguez-Mañas L, Chastin SFM, Alegre LM, et al. Associations between sedentary time, physical activity and bone health among older people using compositional data analysis. PLoS One. 2018;13(10):e0206013.

10. Sahni S, Mangano KM, McLean RR, Hannan MT, Kiel DP. Dietary approaches for bone health: lessons from the Framingham Osteoporosis Study. Curr Osteoporos Rep. 2015;13(4):245-55.

11. Kopiczko A. Assessment of intake of calcium and vitamin D and sun exposure in the context of osteoporosis risk in a study conducted on perimenopausal women. Prz Menopauzalny. 2014;18(2):79-83.

12. Cheraghi Z, Doosti-irani A, Almasi-hashiani A, Baigi V, Mansournia N, Etminan M, et al. The effect of alcohol on osteoporosis: a systematic review and metaanalysis. Drug Alcohol Depend. 2019; 197:197-202.

13. Yang $\mathrm{P}$, Zhang $\mathrm{X}$, Zhang $\mathrm{K}$, Tang $\mathrm{Z}$. Associations between frequency of coffee consumption and osteoporosis in Chinese postmenopausal women. Int J Clin Exp Med. 2015;8(9):15958-66.

14. Buckley L, Humhrey MB. GlucocorticoidInduced Osteoporosis. N Engl J Med. 2018;379:2547-56.

15. Skjødt MK, Ostadahmadli Y, Abrahamsen B. Long term time trends in use of medications associated with risk of developing osteoporosis: Nationwide data for Denmark from 1999 to 2016. Bone. 2019;120:94-100.

16. Ward KD, Klesges RC. A meta-analysis of the effects of cigarette smoking on bone mineral density. Calcif Tissue Int. 2001;68(5):259-70.

17. Al-bashaireh AM, Haddad LG, Weaver M, Chengguo X, Kelly DL, Yoon S. The effect of tobacco smoking on bone mass : an overview of pathophysiologic mechanisms. J Osteoporos. 2018;2018: 1206235.

18. Bijelic R, Milicevic S, Balaban J. The influence of non-preventable risk factors on the development of osteoporosis in postmenopausal women. Mater Sociomed. 2019;31(1):62-5.

19. Akkawi I, Zmerly H. Osteoporosis: Current Concepts. Joints. 2018;6(2):122-7.

20. Yun KY, Han SE, Kim SC, Joo JK, Lee KS. Pregnancy-related osteoporosis and spinal fractures. Obs Gynecol Sci. 2017; 60(1):133-7.

21. Demontiero O, Vidal C, Duque G. Aging and bone loss : new insights for the clinician. Ther Adv Musculoskelet Dis. 2012; 4(2):61-76.

22. Boschitsch EP, Durchschlag E, Dimai HP. Age-related prevalence of osteoporosis and fragility fractures: real-world data from an Austrian Menopause and Osteoporosis Clinic. Climacteric. 2017; 20(2):157-63.

23. Zengin A, Prentice A, Ward KA. Ethnic differences in bone health. Front Endocrinol. 2015;6(24):1-6.

24. Hodges JK, Cao S, Cladis DP, Weaver CM. Lactose intolerance and bone health: the challenge of ensuring adequate calcium intake. Nutrients. 2019;11(4):718.

25. Ji M, Yu Q. Primary osteoporosis in postmenopausal women. Chronic Dis Transl Med. 2015;1(1):9-13.

26. Gallagher JC, Tella SH. Prevention and treatment of postmenopausal osteoporosis. J Steroid Biochem Mol Biol. 2014;142:155-70.

27. Kementerian Kesehatan RI. Data \& Kondisi Penyakit Osteoporosis di Indonesia. Kementerian Kesehatan RI, editor. Jakarta: Pusat Data dan Informasi, 2015; p. 1-6.

28. Hansen D, Bazell C, Pelizzari P, Pyenson B. 
Medicare cost of osteoporotic fractures: the clinical and cost burden of an important consequence of osteoporosis. National Osteoporosis Foundation, 2019. Available from: https://www.milliman. com/en/insight/medicare-cost-ofosteoporotic-fractures.

29. Rosen AHN, Drezner MK. Clinical manifestations, diagnosis, and evaluation of osteoporosis in postmenopausal women [Internet]. UpToDate. 2020 [cited 2020 Jun 28]. p. 1-14. Available from: www.uptodate.com

30. Griffith JF. Identifying osteoporotic vertebral fracture. Quant Imaging Med Surg. 2015;5(4):592-602.

31. Elam REW, Jackson NN, Machua W, Carbone LD, Diamond HS, Lohr KM, et al. Osteoporosis. Medscape. Jan 202021. [cited 2021 Mar 30]. Available from https://emedicine.medscape.com/ article/330598-overview.

32. Lim J, Kim BS, Yoon B, Chang JS, Park C, Koo K. Lessons learned from long-term management of hip fracture in patients with osteopetrosis : a report of nine hips in five patients. J Bone Metab. 2019; 26(3):201-6.

33. Kanis JA, Harvey NC, Johansson H, Odén A, Leslie WD, Mccloskey E V. FRAX Update. J Clin Densitom. 2017;20(3):18. Available from: http://dx.doi.org/ 10.1016/j.jocd.2017.06.022

34. Sheu A, Diamond T. Bone mineral density: testing for osteoporosis. Aust Prescr. 2016;39(2):35-9.

35. Coronado-zarco R, Olascoaga-g A, GarciaLara A, Quinzanos-Fresnedo J, NavaBringas TI, Macías-hern SI. Osteoporosis and sarcopenia nonpharmacological interventions for osteoporosis treatment: systematic review of clinical practice guidelines. Osteoporos Sarcopenia. 2019;5(3):69-77.

36. Connor KMO. Evaluation and treatment of Osteoporosis. Med Clin North Am. 2016;100(4):807-26.
37. Villa JC, Gianakos A, Lane JM. Bisphosphonate treatment in osteoporosis: optimal duration of therapy and the incorporation of a drug holiday. HSS J. 2016;12(1):66-73.

38. An K. Selective estrogen receptor modulators. Asian Spine J. 2016;19(4):787-91.

39. Eastell R, Walsh JS. Anabolic treatment for osteoporosis: teriparatide. Clin Cases Min Bone Metab. 2017;14(2):173-8.

40. Lindsay R, Krege JH, Marin F, Jin L, Stepan JJ. Teriparatide for osteoporosis: importance of the full course. Osteoporos Int. 2016;27:2395-410. Available from: http://dx.doi.org/10.1007/s00198-0163534-6

41. Lewiecki EM. New and emerging concepts in the use of denosumab for the treatment of osteoporosis. Ther Adv Musculoskelet Dis. 2018;10(11):209-23.

42. Deeks ED. Denosumab: a review in postmenopausal osteoporosis. Drugs Aging. 2018;35(2):163-73. Available from: https://doi.org/10.1007/s40266018-0525-7

43. Zaheer S, Leboff M, Lewiecki EM. Denosumab for the treatment of osteoporosis. Expert Opin Drug Metab Toxicol. 2015;11(3):461-70.

44. Gambacciani M, Levancini M. Hormone replacement therapy and the prevention of postmenopausal osteoporosis. Prz Menopauzalny. 2014;13(4):213-20.

45. Tai V, Leung W, Grey A, Reid IR, Bolland MJ. Calcium intake and bone mineral density: systematic review and metaanalysis. BMJ. 2015;351:4183.

46. Yao P, Bennett D, Mafham M, Lin X, Chen Z, Armitage $J$, et al. Vitamin D and calcium for the prevention of fracture a systematic review and meta-analysis. Jama Netw Open. 2019;2(12):e1917789.

47. Jeremiah MP, Unwin BK, Greenawald MH, Carilion VT. Diagnosis and management of osteoporosis. Am Fam Physician. 2015;92(4):261-8. 